\title{
Comment on: 'Are patients with poorer vision more polite? A study examining door closing tendencies in patients with poor vision'
}

\author{
Joshua P. Harvey (D) ${ }^{1}$ \\ Received: 8 October 2018 / Accepted: 25 October 2018 / Published online: 27 November 2018 \\ (c) The Royal College of Ophthalmologists 2018
}

I read with great interest the article by Sidath Wijetilleka and Gwyn Williams titled "Are patients with poorer vision more polite? A study examining door closing tendencies in patients with poor vision" [1]. The authors performed a prospective cohort study of clinic room door closing on two groups of patients, with the group inclusion criteria being based on a visual acuity of more or less than $0.3 \log$ MAR. The authors observed that patients with poor vision had higher rates of door closing and therefore concluded that poor vision is a risk factor for politeness.

I have identified a number of potential confounders that the authors did not report matching for. For instance, women have higher levels of politeness, conscientiousness and orderliness on measures of personality traits [2]. Furthermore, women demonstrate higher rates of visual impairment, therefore the low-VA group may have demonstrated a higher rate of door closing because there were more women in this group [3]. Age is another important confounder as it has been shown that there is a positive correlation between levels of empathy and kindness with advanced age [4]. As there is an increased risk of poor vision with advancing age, this could be another potential confounder [4]. I suggest 12 potential confounding variables, which should be appropriately matched for (Table 1).

Recruiting a cohort large enough to match for these confounders may be challenging, and so I propose the first UK wide multicentre study of door closing outcomes. Furthermore, sub-group analysis could investigate whether being from the south of England has a beneficial effect on politeness as appears to be the case in studies elsewhere [5]. Being a young man with a visual acuity greater than 0.3 $\log$ MAR, I am particularly susceptible to low-levels of
Table. 1 Table highlighting possible confounding factors in the authors' study

\begin{tabular}{lll}
\hline Age & Primary language & Average weekly alcohol status \\
Gender & Socio-economic status & Smoking status \\
Race & Marital status & BMI \\
Country of birth & Diet & Other medical co-morbidities \\
\hline
\end{tabular}

politeness, and so I am interested to know if living in London is protective.

\section{Compliance with ethical standards}

Conflict of interest The author declares no conflict of interest.

\section{References}

1. Wijetilleka S, Williams G. Are patients with poorer vision more polite? A study examining door closing tendencies in patients with poor vision. Eye. 2018;32:1539.

2. Weisberg YJ, Deyoung CG, Hirsh JB. Gender differences in personality across the ten aspects of the big five. Front Psychol. 2011;2:178.

3. Varma R, Vajaranant TS, Burkemper B, Wu S, Torres M, Hsu C et al. Visual impairment and blindness in adults in the united states: demographic and geographic variations from 2015 to 2050. JAMA Ophthalmol. 2016;134:802-9.

4. Venter E. Bridging the communication gap between Generation $Y$ and the Baby Boomer generation. Int $\mathrm{J}$ Adolesc Youth. 2017;22:497-507.

5. Culpeper J, Gillings M. Politeness Variation in England: A NorthSouth Divide? In: Brezina V, Love, R, Aijmer K, editors.Corpus Approaches to Contemporary British Speech. Taylor \& Francis: Routledge; 2018. pp 123-8.
Joshua P. Harvey

Joshua.harvey@doctors.org.uk

1 Ophthalmology Department, King's College Hospital, London, United Kingdom 


\title{
Response to: Comment on 'Are patients with poorer vision more polite? A study examining door closing tendencies in patients with poor vision'
}

\author{
S. Wijetilleka ${ }^{1} \cdot$ G. Williams ${ }^{1}$
}

Received: 24 October 2018 / Accepted: 25 October 2018 / Published online: 27 November 2018

(c) The Royal College of Ophthalmologists 2018

We, the authors, thank Dr Joshua Harvey for supplying a very valid list of possible confounding factors affecting our study. We certainly agree that age is a confounding factor, with younger patients with good vision less likely to close the door behind them in clinic. We are somewhat surprised to hear that living in London may be a protective factor and suggest that Welsh patients are on the whole equally, if not more, polite, with one of the authors having worked at both locations. It may be the case, however, that the English place more value on the superficial manifestation of politeness in such acts as door closing, and therefore we suggest including an anthropologist in any future largescale study to examine significant cultural differences between the various nations that make up the United
Kingdom. The authors also debate some of the other listed confounding factors, including how a person's marital status and diet could confound their ability to close a door behind them after leaving clinic, although it was considered beyond the scope of the study to evaluate these. The authors certainly support the idea of further research into the subject and the first UK-wide multicentre study on door closing outcomes considering these factors is a valid idea.

\section{Compliance with ethical standards}

Conflict of interest The authors declare that they have no conflict of interest.

\section{S. Wijetilleka}

sidwijetilleka@doctors.net.uk

1 Singleton Hospital, Sketty Lane, Swansea, UK 


\title{
Real-world experience at a Scottish university teaching hospital regarding the tolerability and persistence with topical Ciclosporin $0.1 \%$ (Ikervis) treatment in patients with dry eye disease
}

\author{
Jennifer Hind ${ }^{1}$ Elisabeth Macdonald ${ }^{1}$. David Lockington $\mathbb{B}^{1}$ \\ Received: 2 October 2018 / Accepted: 12 November 2018 / Published online: 29 November 2018 \\ (c) The Royal College of Ophthalmologists 2018
}

\section{Introduction}

The recent DEWS II report has recognised the inflammatory component of dry eye disease (DED), and highlighted the use of topical ciclosporin as a management option [1]. Ciclosporin A $(1 \mathrm{mg} / \mathrm{ml})$ in a cationic emulsion (Ikervis, Santen) was approved for once daily use by the Scottish Medical Consortium for the treatment of severe keratitis in adult patients with DED that has not improved despite treatment with tear substitutes in October 2015. The key published studies (SANSIKA [2] and SICCANOVE [3]) both reported issues with drop instillation pain (29.2-54.5\%) and subsequent discontinuation of treatment $(9.9-10.4 \%)[2,3]$. We wished to evaluate our initial real-world experiences with Ikervis in terms of patient tolerability and persistence of therapy.

\section{Methods}

All patients prescribed topical Ikervis by two consultant ophthalmologists from October 2015 to May 2018 were identified from the NHS Greater Glasgow and Clyde pharmacy database. Their electronic patient record was reviewed to identify patient demographics, indication, concurrent topical medication, adverse events and whether Ikervis was tolerated or discontinued.

David Lockington

davidlockington@hotmail.com

1 Tennent Institute of Ophthalmology, Gartnavel General Hospital, 1053 Great Western Road, Glasgow G12 0YN, UK

\section{Results}

A total of 52 patients were identified (13 male, 39 female). The mean age was 58 years (range 19-91). The underlying aetiology for keratitis and DED in this patient group is outlined in Table 1. Mean duration of treatment with Ikervis was 11 months (median 8.5; range 2-30). Sixty three percent of patients (33/52) were also treated with a tapering dose of topical steroids for the first month during the initiation phase of Ikervis use. All patients remained on long-term topical lubrication treatment at least 4 times per day. At last casenote review in September 2018, Ikervis was well tolerated and treatment persisted successfully in $88 \%$ (46/52) of patients. Only 6 patients discontinued Ikervis due to intolerance in the time period identified, although 2 were able to restart and persist (intolerant of treatment $4 / 52 ; 7.7 \%$ ). The reason stated for lack of persistence was local irritation, burning, or stinging in all 6 cases $(11.5 \%)$. These symptoms were manifested despite initial concurrent treatment with 1 month of topical steroids in 5 out of the 6 patients.

Table 1 Table detailing underlying aetiology for keratitis and dry eye disease in this patient group prior to starting Ikervis treatment

\begin{tabular}{ll}
\hline Other associated conditions contributing to dry eye symptoms & $N(\%)$ \\
\hline Sjogrens/Rheumatoid Arthritis & $21(40.4)$ \\
Blepharitis/lid margin disease & $11(21.6)$ \\
Allergy/atopic eye disease & $6(11.5)$ \\
Exposure/neurotrophic cornea/thyroid eye disease & $3(5.8)$ \\
Salzmann nodules & $2(3.8)$ \\
Pterygium & $2(3.8)$ \\
Previous penetrating keratoplasty & $1(1.9)$ \\
Vitamin A deficiency & $1(1.9)$ \\
Chemotherapy-related dry eye & $1(1.9)$ \\
Thygeson's keratitis & $1(1.9)$ \\
Other (zoster, ectodermal dysplasia, unknown) & $3(5.8)$ \\
\hline
\end{tabular}




\section{Conclusion}

Ikervis has been marketed as a dry eye product with less tolerance issues than other forms of topical ciclosporin (predominantly due to vehicle differences) and effective as a once daily dose (reducing instillation frequency and associated discomfort) [4]. In our study, Ikervis was tolerated in the majority of these DED patients with reasonable treatment duration (mean 11 months). However, local ocular irritation led to intolerance of treatment in a small number of patients (7.7\%). It has been suggested that concurrent use of topical steroids during the initiation of topical ciclosporin use can improve tolerance by reducing local ocular side effects [5]. This appeared to be the experience for most of our patients, but was not universal, reflecting the severity and complexity of DED. The SANSIKA and SICCANOVE studies suggested that initial ocular irritation decreased with longterm Ikervis use [2, $3,6,7]$. Our small study provides real-world experience data regarding the use, persistence and tolerability of topical Ikervis outside the controlled confines of these key clinical trials.

\section{Compliance with ethical standards}

Conflict of interest The authors declare that they have no conflict of interest.

\section{References}

1. Jones L, Downie LE, Korb D, Benitez-Del-Castillo JM, Dana R, Deng SX, et al. TFOS DEWS II management and therapy report. Ocul Surf. 2017;15:575-628.

2. Leonardi A, Van Setten G, Amrane M, Ismail D, Garrigue JS, Figueiredo FC, et al. Efficacy and safety of $0.1 \%$ cyclosporine A cationic emulsion in the treatment of severe dry eye disease: a multicenter randomized trial. Eur $\mathrm{J}$ Ophthalmol. 2016;26:287-96.

3. Baudouin C, Figueiredo FC, Messmer EM, Ismail D, Amrane M, Garrigue JS, et al. A randomized study of the efficacy and safety of $0.1 \%$ cyclosporine A cationic emulsion in treatment of moderate to severe dry eye. Eur J Ophthalmol. 2017;27:520-30.

4. Lallemand F, Daull P, Benita S, Buggage R, Garrigue JS. Successfully improving ocular drug delivery using the cationic nanoemulsion, novasorb. J Drug Deliv. 2012;604204:27.

5. Sheppard JD, Donnenfeld ED, Holland EJ, Slonim CB, Solomon R, Solomon KD, et al. Effect of loteprednol etabonate $0.5 \%$ on initiation of dry eye treatment with topical cyclosporine $0.05 \%$. Eye Contact Lens. 2014;40:289-96.

6. Leonardi A, Messmer EM, Labetoulle M, Amrane M, Garrigue JS, Ismail D, et al. Efficacy and safety of $0.1 \%$ ciclosporin A cationic emulsion in dry eye disease: a pooled analysis of twodoublemasked, randomised, vehicle-controlled phase III clinical studies. Br JOphthalmol. 2018 Mar 15. pii: bjophthalmol-2017-311801. https://doi.org/10.1136/bjophthalmol-2017-311801.

7. Baudouin C, de la Maza MS, Amrane M, Garrigue JS, Ismail $\mathrm{D}$, Figueiredo FC, et al. One-year efficacy and safety of $0.1 \%$ cyclosporine a cationic emulsion in the treatment of severe dry eye disease. Eur J Ophthalmol. 2017;27:678-85.

\title{
Unique presentation of congenital cataract concurrent with microcornea, microphthalmia plus posterior capsule defect in monozygotic twins caused by a novel GJA8 mutation
}

\author{
Hongfang Zhang ${ }^{1} \cdot$ Zhenji Chen $^{1} \cdot$ Kaiwen $\mathrm{He}^{1} \cdot$ Pingjun Chang ${ }^{1} \cdot$ Yinying Zhao ${ }^{1} \cdot$ Xiufeng Huang $^{1} \cdot{\mathrm{Jin} \mathrm{Li}^{1}}^{1}$ \\ Zibing Jin $\left(^{1}\right)^{1}$ Yun-e Zhao ${ }^{1}$
}

Received: 22 December 2017 / Revised: 15 July 2018 / Accepted: 5 October 2018 / Published online: 29 November 2018

(c) The Author(s) 2018. This article is published with open access

\footnotetext{
These authors contributed equally: Hongfang Zhang and Zhenji Chen

Zibing Jin

jinzb@mail.eye.ac.cn

$\triangle$ Yun-e Zhao

zyehzeye@126.com

1 The Eye Hospital of Wenzhou Medical University, School of Ophthalmology and Optometry, The State Key Laboratory of Ophthalmology, Optometry and Vision Science, 325027

Wenzhou, China
}

Congenital cataracts are the most common diseases which account for 10-30\% of blindness in children [1]. Multiple genetic mutations contribute to the progression of this genetically heterogeneous and complex disease. Among the reported causative congenital cataract mutations, approximately one quarter are connexin genes, including Connexin 46 which is encoded by GJA3 and Connexin 50 which is encoded by GJA8 [2].

In this study, we encountered four generations of a Chinese family with bilateral congenital cataracts at the Eye Hospital of Wenzhou Medical University. Among the four affected 
Fig. 1 Anterior segment photographs of the affected individuals

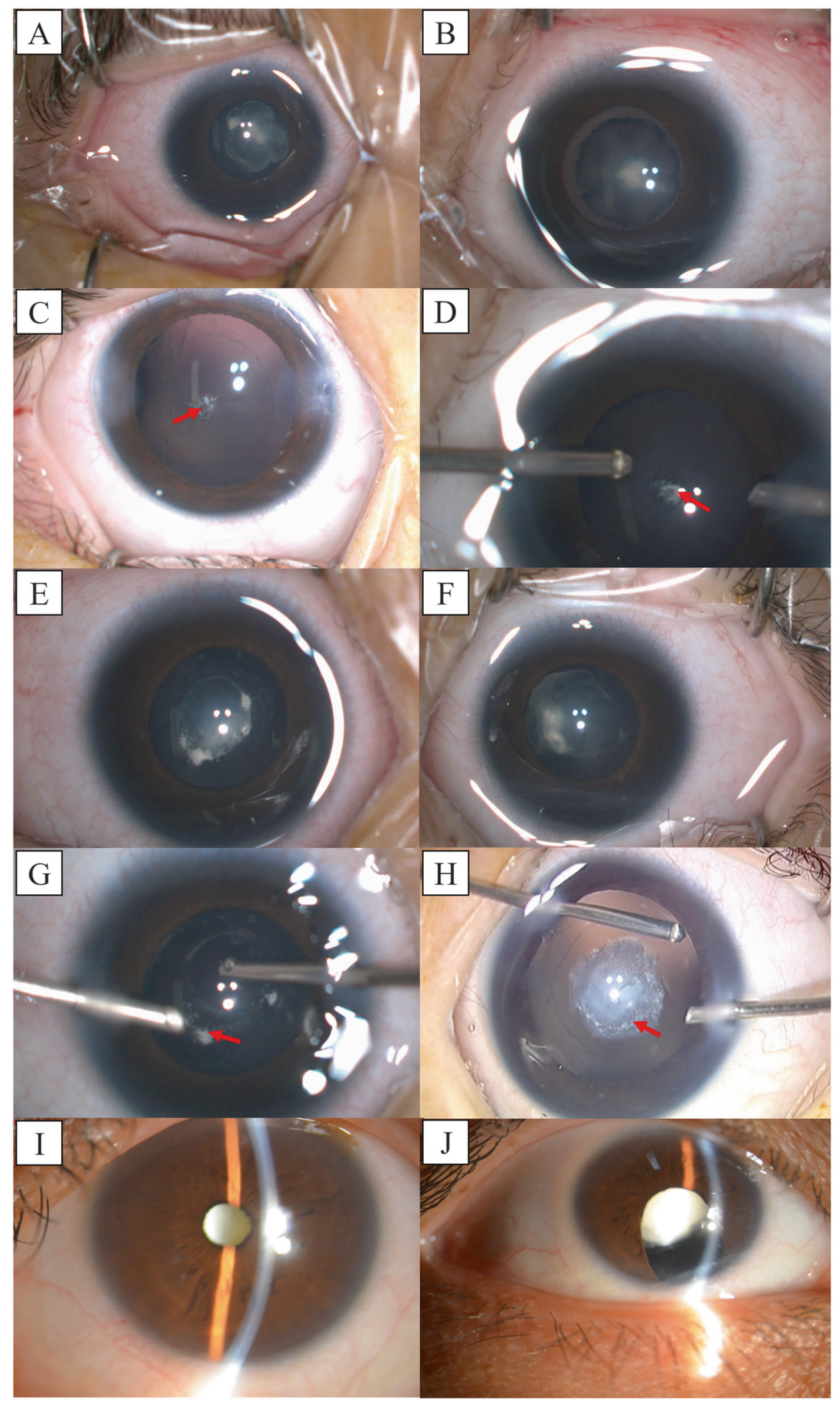


A

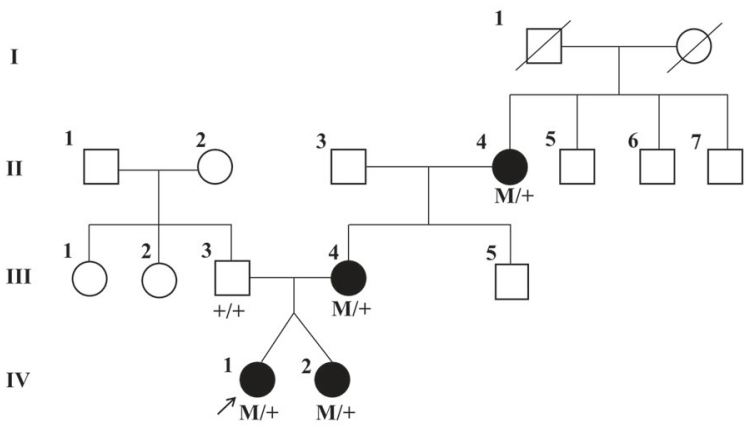

$\mathrm{C}$

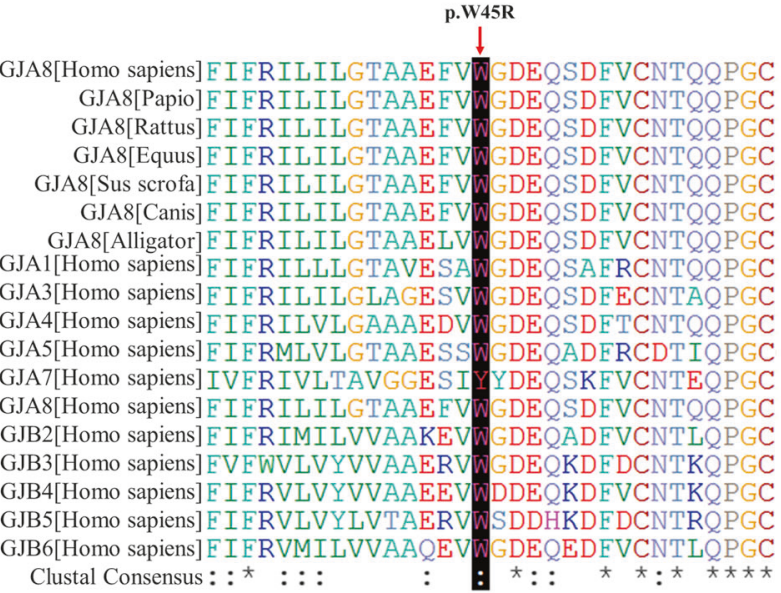

$\mathrm{B}$

GJA8

c. $133 T>C$

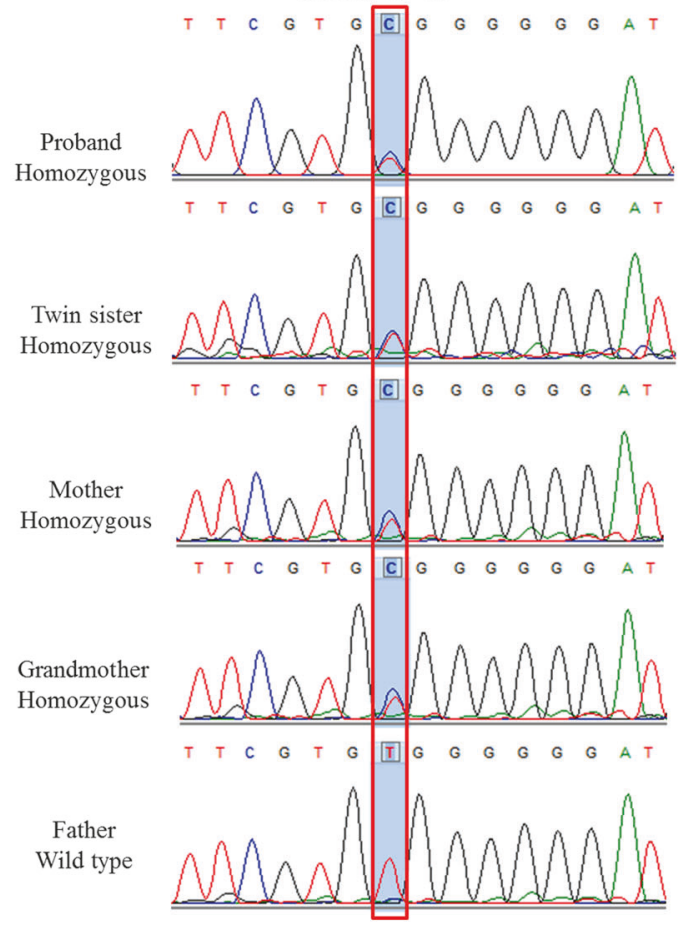

Fig. 2 A Pedigree of four generations of the family with autosomal dominant cataracts. B Chromatograms showing the DNA sequence analysis in the GJA8 mutation pedigree. C A multiple-sequence alignment of the amino-acid sequence in GJA8 from various species and isoforms

individuals in this family, two are twin sisters. The twins were diagnosed with bilateral congenital cataracts with microcornea, microphthalmia and posterior capsule defect (PCD). Photographs were obtained from a video of the surgery and confirmed the ophthalmologist's diagnosis. Anterior segment photographs of proband (Fig. 1A, B) and her twin sister (Fig. 1E, F) show nuclear cataracts. Their posterior capsule photographs (Fig. 1C, D, G, H) demonstrate posterior polar cataracts with posterior capsule defects. Photographs of their grandmother (Fig. 1I, J) show full cataracts.

To investigate the causative mutation in this family, we first performed whole exome sequencing on DNA from subject IV-1 (Fig. 2A) and identified a novel missense mutation, c. T133C, in GJA8. Sanger sequencing confirmed that the mutation co-segregated with all affected individuals and was not observed in the unaffected family member or in 100 unrelated controls (Fig. 2B). The mutation resulted in a missense amino-acid change, tryptophan to arginine, which was absent in dbSNP137, $1000 \mathrm{G}$, ESP6500 and ExAC databases. The arginine residue at position 45 is highly conserved across species and isoforms (Fig. 2C). Moreover, p. W45R is predicted to be pathogenic by SIFT (score 0.00 out of 1.00, "damaging"), Polyphen-2 (score 0.999 out of 1.000, "probably damaging") and Mutation Taster (score 0.00 out of
1.00, "damaging"). Based on the above evidences, we can determine that the novel mutation (c.133 T > C, p.W45R) in GJA8 is the pathogenic mutation in this family.

In conclusion, our study identifies a novel missense mutation in GJA8 in a Chinese family with congenital cataracts using WES, thereby expanding the existing spectrum of GJA8 mutations.

\section{Compliance with ethical standards}

Conflict of interest The authors declare that they have no conflict of interest.

Open Access This article is licensed under a Creative Commons Attribution 4.0 International License, which permits use, sharing, adaptation, distribution and reproduction in any medium or format, as long as you give appropriate credit to the original author(s) and the source, provide a link to the Creative Commons license, and indicate if changes were made. The images or other third party material in this article are included in the article's Creative Commons license, unless indicated otherwise in a credit line to the material. If material is not included in the article's Creative Commons license and your intended use is not permitted by statutory regulation or exceeds the permitted use, you will need to obtain permission directly from the copyright holder. To view a copy of this license, visit http://creativecommons. org/licenses/by/4.0/. 


\section{References}

1. Reddy MA, Francis PJ, Berry V, Bhattacharya SS, Moore AT. Molecular genetic basis of inherited cataract and associated phenotypes. Surv Ophthalmol. 2004;49:300-15.
2. Shiels A, Bennett T, Hejtmancik M, Fielding J. Cat-Map: putting cataract on the map. Mol Vision. 2010;16:2007-15.

\title{
Is post-operative perfluorocarbon liquid tamponade for macula-on giant retinal tear safer than silicone oil?
}

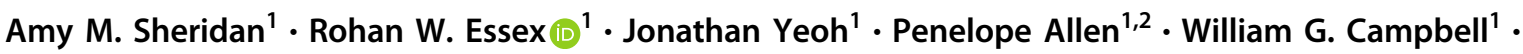 \\ Thomas L. Edwards (1) ${ }^{1,2}$
}

Received: 5 August 2018 / Revised: 25 September 2018 / Accepted: 26 September 2018 / Published online: 7 December 2018

(c) The Royal College of Ophthalmologists 2018

The incidence of unexplained central vision loss immediately following removal of silicone oil (ROSO) has been reported at between $3.3 \%$ [1] and 5.9\% [2], but may be considerably higher in certain retinal detachment subgroups. For example, the rate of ROSO maculopathy after macula-on giant retinal tear (GRT) repair was reported as high as $50 \%$ [1] in this journal, perhaps suggesting maculaon GRTs (Fig 1), or indeed any macula-on retinal detachment, are uniquely susceptible to ROSO maculopathy.

Perfluorocarbon heavy liquid (PFCL) as a short-term post-operative tamponade agent in GRT repair is a safe and effective alternative to silicone oil ( $\mathrm{SiO})$ or gas. This technique, first described by Bottoni [3] and subsequently by others [4-7], is used to manage all GRT detachments at the Royal Victorian Eye and Ear Hospital. PFCL remains in the eye for approximately 14 days, before exchange with fluid, air or gas. To investigate whether removal of short-term PFCL tamponade resulted in a lower rate of unexplained vision loss than ROSO in macula-on GRT detachments, we performed a consecutive retrospective review of all maculaon GRT repairs between 19 August 2007 and 12 December 2016. Best-corrected visual acuity (VA) was recorded at initial presentation, and 3 months following PFCL removal. The outcome of the procedure was determined at 3 months.

Thomas L. Edwards

thomas.edwards@unimelb.edu.au

Royal Victorian Eye and Ear Hospital, Melbourne, Australia

2 Centre for Eye Research Australia, Royal Victorian Eye and Ear Hospital, Melbourne, Australia
Statistical analysis was performed using a paired student's $t$ test assuming equal variance (alpha $=0.05$ ).

A total of 25 eyes in 24 patients (mean age 57 years; range 39-79 years) comprising 4 female patients (16.7\%) and 20 male patients $(83.3 \%)$ were included in the study cohort (Table 1). The mean (range) duration of PFCL tamponade was 14.6 days, (10-28 days) before removal and exchange either with 20 or $25 \%$ SF6 gas $(n=13,52 \%)$, air $(n=7$, $28 \%)$ or balanced salt solution $(n=5,20 \%)$. The mean baseline VA was 76 letters. The mean VA 3 months post-

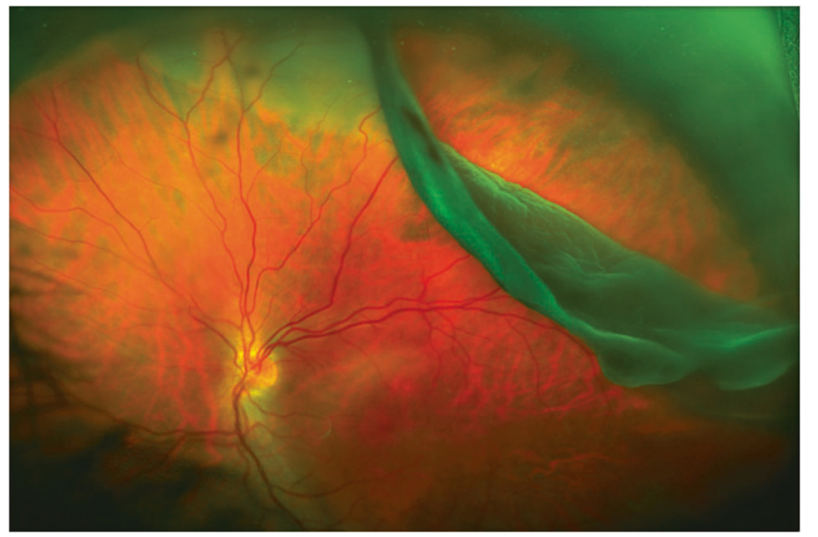

Fig. 1 Wide-field fundus photograph of the left eye showing a superotemporal giant retinal tear (GRT). A characteristic feature of this type of retinal detachment is posterior folding of the detached retina. Repositioning of the fold is facilitated by intra-operative perfluorocarbon liquid (PFCL) tamponade. Intra- or post-operative slippage can occur when the PFCL is exchanged for gas or, more rarely, silicone oil. An effective alternative is short-term post-operative tamponade with PFCL, which minimises the risk of retinal slippage 


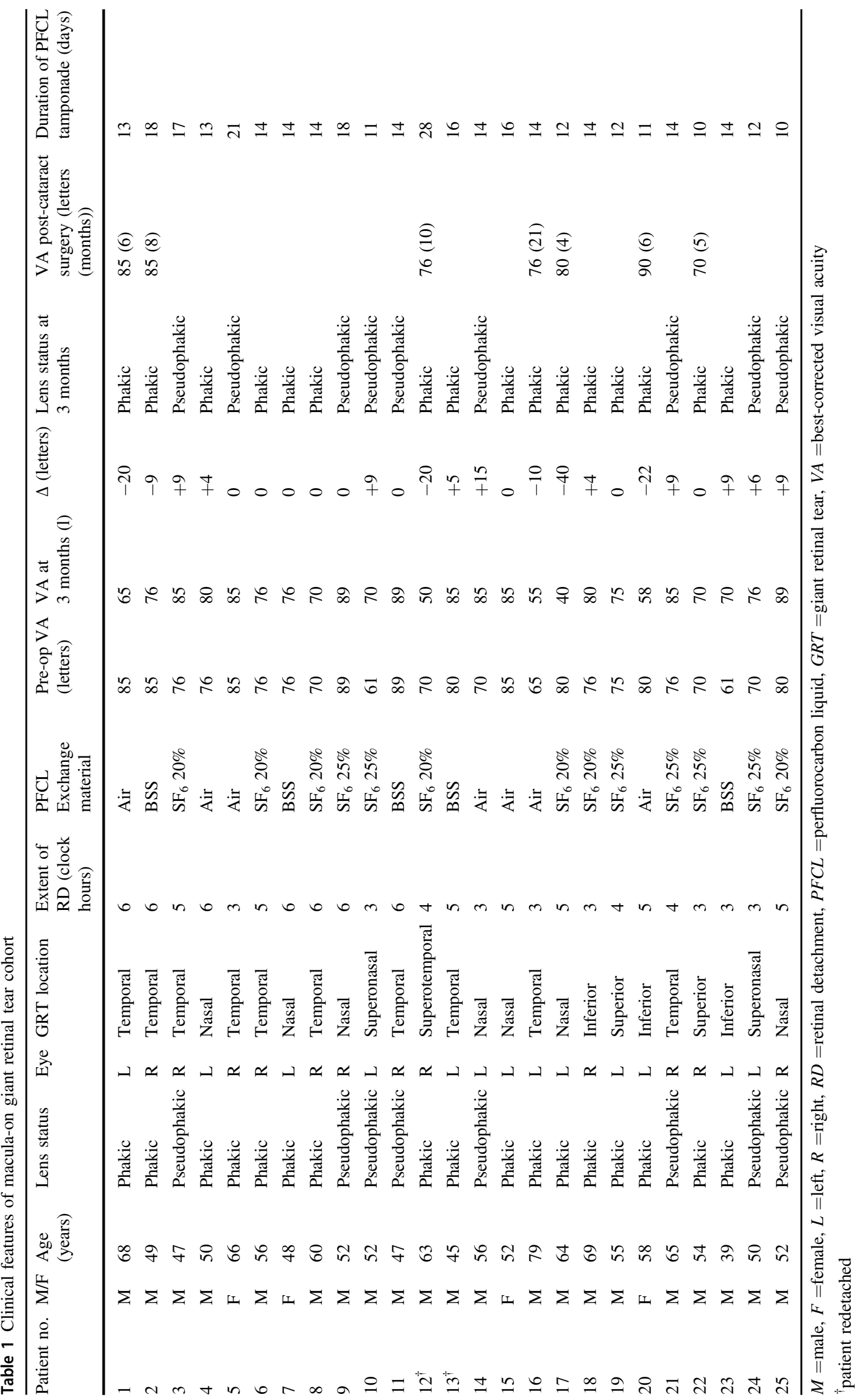


GRT repair was 76 letters, improving to 80 letters after a total of seven patients underwent cataract surgery following a median interval of 6 months (range 4-21 months). This was significantly better than the baseline VA $(p<0.001)$. The prevalence of visual loss $\geq 10$ letters at 3 months was 4 (16\%), which improved to baseline or better in all four following subsequent cataract surgery. Redetachment (maculaon) occurred in two out of 25 patients (8\%) following removal of PFCL due to smaller missed breaks. Both were successfully repaired with cryotherapy and gas tamponade.

In keeping with other reports [5-7], short-term use of post-operative PFCL in this study was associated with good primary and final anatomical success rates. Notably, in contrast to the reported high rate of vision loss after ROSO in the same patient group i.e. macula-on detachments $[1,8$, 9] there were no unexplained visual acuity losses in our series. PFCL may thus mitigate the high incidence of unexplained vision loss after ROSO in those eyes where a good visual outcome is expected. Vitreoretinal surgeons should consider PFCL as an alternative to $\mathrm{SiO}$ or gas as a post-operative tamponade agent in macula-on GRT repair.

Acknowledgements Additional members of the Vitreoretinal Unit of the Royal Victorian Eye and Ear Hospital who performed surgery on these cases: Drs M F McCombe, D Chiu, R Dawkins, E Roufail, J B Clark and D Fabinyi.

Ethical approval The study protocol was approved by the Royal Victorian Eye and Ear Human Research Ethics Committee (HREC approval $07 / 759 \mathrm{H}$ ) and all procedures were conducted in accordance with the tenets of the Declaration of Helsinki 7th revision.

\section{Compliance with ethical standards}

Conflict of interest The authors declare that they have no conflict of interest.

\section{References}

1. Moya R, Chandra A, Banerjee PJ, Tsouris D, Ahmad N, Charteris DG. The incidence of unexplained visual loss following removal of silicone oil. Eye. 2015;29:1477-82.

2. Roca JA, Wu L, Berrocal M, Rodriguez F, Alezzandrini A, Alvira $\mathrm{G}$, et al. Un-explained visual loss following silicone oil removal: results of the Pan American Collaborative Retina Study (PACORES) Group. Int J Retin Vitr. 2017;3:26.

3. Bottoni F, Bailo G, Arpa P, Prussiani A, Monticelli M, de Molfetta V. Management of giant retinal tears using perfluorodecalin as a postoperative short-term vitreoretinal tamponade: a long-term follow-up study. Ophthalmic Surg. 1994;25:365-73.

4. Campbell WG, McCombe MF. The management of giant retinal tears with short-term tamponade with perfluoro-N-octane and transscleral diode photocoagulation. 29th Annual Scientific Meeting of the Royal Australian and New Zealand College of Ophthalmologists, Sydney; 1997

5. Sirimaharaj M, Balachandran C, Chan WC, Hunyor AP, Chang AA, Gregory-Roberts J, et al. Vitrectomy with short term postoperative tamponade using perfluorocarbon liquid for giant retinal tears. Br J Ophthalmol. 2005;89:1176-9.

6. Randolph JC, Diaz RI, Sigler EJ, Calzada JI, Charles S. 25-gauge pars plana vitrectomy with medium-term postoperative perfluoro-noctane for the repair of giant retinal tears. Graefes Arch Clin Exp Ophthalmol. 2016;254:253-7.

7. Eiger-Moscovich M, Gershoni A, Axer-Siegel R, Weinberger D, Ehrlich R. Short-term vitreoretinal tamponade with heavy liquid following surgery for giant retinal tear. Curr Eye Res. 2017;42:1074-8.

8. Tode J, Purtskhvanidze K, Oppermann T, Hillenkamp J, Treumer F, Roider J. Vision loss under silicone oil tamponade. Graefes Arch Clin Exp Ophthalmol. 2016;254(8): $1465-71$.

9. Christensen UC, la Cour M. Visual loss after use of intraocular silicone oil associated with thinning of inner retinal layers. Acta Ophthalmol. 2011;90:733-7.

\title{
Trainee confidence managing ocular trauma
}

\author{
Amy-lee Shirodkar ${ }^{1} \cdot$ Damien CM Yeo $\mathbb{D}^{1} \cdot$ Mr. Gary Shuttleworth ${ }^{2}$
}

Received: 29 November 2018 / Accepted: 7 December 2018 / Published online: 7 January 2019

(c) The Royal College of Ophthalmologists 2019

\author{
$\triangle$ Amy-lee Shirodkar \\ a-1.s@gmx.com \\ Cardiff Eye unit, UHW, Cardiff, UK \\ 2 Ophthalmology, Singleton Hospital, Swansea, UK
}

Morris et al. [1], showed a reduction in serious cases of ocular trauma between 1992 and 2009 by fourfold and there is a real risk that repairing ocular trauma is now so 
infrequently performed that a large portion of the ophthalmic community has insufficient skills to carry out repeatabily safe and secure repairs. As part of training, an Ophthalmology trainee is expected to be able to perform a minimum of two surgical repairs of ocular and adnexal tissues in 7 years. We surveyed a cross-section of Ophthalmic trainees, of all training grades, for their perceived levels of confidence and experience managing ocular trauma. Totally, $96 \%$ of Welsh trainees completed the survey, over a 12 month period they were exposed to 43 cases of ocular trauma repairs, an average of 2 per trainee, ranging from none to 6 . The infrequency and unpredictability mean that experiences may be difficult to obtain and limited by the time, with $41 \%$ of trainees believing they would not achieve two assessments. Overall, $78 \%$ of trainees reported negative confidence when performing surgery for cases of ocular trauma, which were associated with an average of one case or less a year and not having completed cornea or oculoplastics training placements. Trainees felt if they were encouraged to perform transferable steps, for example a trainee would learn the skills to repair conjunctival lacerations by suturing a conjunctival graft during pterygium surgery, their confidence would increase. Despite attending simulation events and courses, in the trainee's mind there is still no substitute for personal experience as interestingly no significant differences in perceived confidence were apparent between trainees who had attended trauma courses to those that had not.

These results will be of interest both to those constructing curricula and those delivering training of our future Ophthalmologists. With the shift towards safer 'in-hours' operating, luck of exposure and changes to working hours, priority should be given with short notice cancellation for a trainee's routine clinical activity. Our survey is a warning that if we are to continue providing safe out of hours services, teaching resources require proper assessment and development to meet these needs.

\section{Compliance with ethical standards}

Conflict of interest The authors declare that they have no conflict of interest.

Publisher's note: Springer Nature remains neutral with regard to jurisdictional claims in published maps and institutional affiliations.

\section{References}

1. Morris DS, Willis S, et al. The incidence of serious eye injury in Scotland: a prospective study. Eye. 2014;28:34-40. 